\title{
Tarefas para a aprendizagem de língua estrangeira em ambiente digital: focando o papel do aluno
}

\author{
Patrícia da Silva Campelo Costa Barcellos (UFRGS) - patricia.campelo@ufrgs.br \\ Eunice Polonia (UFRGS) - profepoloniaufrgs@gmail.com \\ Mariana Backes Nunes (UNISINOS) - marianabackesnunes@gmail.com
}

Resumo: Com a introdução das tecnologias de informação e comunicação e a exploração do seu potencial na educação, os paradigmas e os papéis dos participantes no processo de ensino-aprendizagem têm sido revisitados. Neste estudo, avaliamos alguns desdobramentos de uma tarefa de escrita colaborativa de fanfictions por alunos de inglês, em contexto universitário, com a utilização da ferramenta de escrita colaborativa ETC. O nosso objetivo é investigar de que maneira uma tarefa de reformulação dos textos no ambiente digital associa-se à autonomia desse aluno. Os dados mostram que a proposição de tarefas de escrita colaborativa significativas pode fomentar a exploração construtiva das interações, de modo a potencializar a aprendizagem de inglês como língua estrangeira dos envolvidos e uma postura autônoma por parte dos graduandos. Identificamos através da experiência aqui descrita que a tarefa de escrita colaborativa pode, portanto, constituir-se em uma prática que dá ênfase ao processo de criação e reelaboração ativa a partir de parcerias provocadoras, que desse modo iniciam o seu agir autônomo e consolidam aprendizagens.

Palavras-chave: Tecnologia e educação. Escrita colaborativa. Autonomia. Papel do aluno.

\section{Tasks for foreign language learning in a digital environment: focusing on the student's role}

\begin{abstract}
Upon the introduction of information and communication technologies and exploitation of their potential in education, the paradigms and the roles of participants in the teaching and learning process have been revisited. In this study, we evaluate some outcomings of a task aimed at writing fanfictions collaboratively by English students, in the academic context, with the use of the digital tool ETC. Our goal is to examine how a task of text reformulation in the digital environment is associated with autonomy. Data show that the introduction of significant collaborative writing tasks can foster the exploration of constructive interaction in order to potentialize English learning as well as an autonomous attitude. We have identified through the experience described here that collaborative writing tasks can, therefore, constitute a practice that emphasizes an active process of creation and reformulation promoting provocative partnerships among students, who thus behave more autonomously and consolidate their learning.
\end{abstract}

Key-words: Technology and education. Collaborative writing. Autonomy. Students' role.

\section{Introdução}

Na discussão acerca dos paradigmas educacionais a serem adotados quando são inseridas as novas tecnologias na cena educacional, em estudos anteriores 
(BARCELLOS, 2017; POLONIA, 2003; NEVADO, 2001; VETROMILLE-CASTRO, 2007) destacam-se os novos papéis para os participantes do processo de ensinoaprendizagem, entendendo-se como papel tanto a parte que professores e alunos devem desempenhar para realizar tarefas de aprendizagem como os relacionamentos sociais e interpessoais entre os participantes (NUNAN, 1993).

Polonia (2007) observa que a educação a distância exige uma revisão dos modos de ensinar e aprender, já que o ambiente digital dissolve as características de uma aula presencial como linearidade, hierarquia, barreiras espaciais e fragmentação temporal, favorecendo, assim, a descentração e as trocas sociocognitivas. A produção é o corpo e a participação dentro da sala de aula virtual. A organização em torno de tarefas interativas interdependentes pode proporcionar a exploração construtiva das interações reflexivas produzidas por comunidades virtuais de aprendizagem de inglês como língua estrangeira (LE), desde que se tenha: o favorecimento do foco na forma e no sentido; a realização de tarefas cooperativas; a intervenção do professor fornecendo evidência negativa; além do desenvolvimento de tarefas em uma plataforma digital que possibilite a intercomunicação assíncrona e síncrona.

Ademais, a inserção de tecnologias de informação e comunicação na sala de aula de LE serve como alavanca para a mudança de paradigma pedagógico e do papel dos aprendizes, centrando-os mais na aprendizagem e favorecendo um papel mais ativo, voltado para um desenvolvimento de conhecimento mais personalizado dos alunos. Esta atividade no contexto de LE se dá por meio da realização de tarefas, as quais trazem pressuposições implícitas, por parte do professor, relativas ao papel do aluno (RICHARDS; RODGER, 1986).

Neste artigo, focalizamos este intrincado relacionamento em uma experiência desenvolvida com uma turma a distância como suporte às atividades presenciais de inglês como LE, em contexto universitário, buscando responder à seguinte questão pedagógica relativa à aprendizagem de língua estrangeira em ambiente digital: De que maneira a tarefa de reformulação em ambiente digital promove a autonomia do aluno? Baseado em estudos anteriores (BROCH, 2008), observamos indícios de promoção da autonomia a partir de tarefas que requerem a participação ativa do aluno dentro de um processo interativo em ambiente digital.

\section{A Tarefa e o Papel do Aprendiz}

O conceito de tarefa dentro da abordagem comunicativa para o ensino e aprendizagem de inglês como língua estrangeira é descrito por Bygate, Skehan e Swain (2001) como uma atividade contextualizada que requer dos aprendizes o uso da língua, com ênfase no significado e com uma conexão ao mundo real, a fim de alcançar um objetivo. Nesta investigação, adotaremos a visão alternativa de tarefa, seguida por vários autores, notadamente por Swain (SWAIN, 1998; SWAIN; LAPKIN, 2001) e Breen e Candlin (1980), de que uma tarefa possa ainda ser considerada comunicativa, mesmo se o aprendiz focalizar explicitamente na forma ao tentar expressar algo que ele queira dizer de forma tão correta e coerente quanto consiga (SWAIN; LAPKIN, 2001 2001).

Nunan (1993) sugere um esquema para análise de componentes básicos de uma tarefa comunicativa para a aula presencial tradicional que abrange: objetivos, insumo e atividades. Tais elementos podem também ser analisados dentro do desenvolvimento de 
um curso em ambiente digital, pois implicam em certos papéis do professor e dos alunos e, juntamente com esses, são influenciados pelos contextos (settings). Ao mesmo tempo, uma tarefa refletirá as pressuposições a respeito das contribuições que os aprendizes podem fazer ao processo de aprendizagem (RICHARDS; RODGERS, 1986).

Dentro da abordagem comunicativa, o aprendiz tem um papel ativo, contribuindo e negociando, além de receber insumo ou iniciação interativa por parte do professor. Há uma convergência de autores diversos (BENSON, 1997, OXFORD, 2003) no sentido de que o aprendiz tome para si a responsabilidade por sua própria aprendizagem, desenvolvendo autonomia e estratégias/ habilidades de aprender a aprender.

A autonomia, segundo Benson (2001), é a capacidade do indivíduo de controlar a sua própria aprendizagem, resultado do processo de construção e reelaboração de conhecimento a partir de experiências pretéritas coletivas ou individuais de tomada de decisões na solução de problemas. Ainda, Nicolaides (2003) aponta que a autonomia implica utilizar conhecimentos aprendidos/adquiridos para modificar o meio social de forma responsável. Assim, um aprendiz autônomo deve saber definir suas metas; identificar-se como responsável ativo na busca e aquisição do conhecimento; estar apto a estabelecer os métodos de busca do conhecimento dentro e fora do meio acadêmico; conseguir avaliar-se durante o processo de aprendizagem, detectando dificuldades e criando soluções para enfrentá-las; e desenvolver a capacidade de exercer autonomia como aprendiz de acordo com as possibilidades do contexto com responsabilidade e consciência de seu papel de transformador social (NICOLAIDES, 2003).

O papel da prática educativo-crítica pode ser o de dar condições para que os estudantes, através da formação de uma curiosidade epistemológica, assumam-se enquanto autores de seu pensar e fazer criador de si e da sociedade (FREIRE, 1996). Entende-se aqui autonomia como o processo contínuo de formação de uma identidade intelectual (PAPERT, 1994) através do engajamento em experiências de tomada de consciência, de decisão e de responsabilidade de si diante do grupo e como grupo diante de si. Assim, um ambiente interpessoal inclusivo e cooperativo à liberdade de escolha dos aprendizes pode contribuir para uma maior autonomia (LITTLEWOOD, 1999).

$\mathrm{O}$ aprendiz autônomo deve saber agir de forma interdependente, isto é, negociar suas necessidades e aspirações com as de seu grupo a fim de colaborar para um bem comum (BREEN; MANN, 1997; BENSON, 2001). A isso, acrescenta-se que a colaboração envolve o reconhecimento dos indivíduos como parte de uma atividade cooperativa, e supõe a aceitação de suas contribuições em serviço de um objetivo maior. Finalmente, grupos colaborativos constroem coerência nas relações sociais e no conhecimento localizado e distribuído em seus membros. Com isso, o "desempenho assistido" e a aprendizagem que esse conduz são a razão e o resultado de relações mediadas pelo desejo em comum de alcançar um objetivo. O resultado da cooperação é, ao mesmo tempo, o surgimento de novo conhecimento e o crescimento do grupo. Mas para que tal ocorra, contudo, a colaboração deve capacitar os indivíduos a empenhar-se em um contínuo envolvimento em futuras atividades conjuntas (DONATO, 2004).

\section{O Papel do Aprendiz e a Mediação do Ambiente Digital}

A teoria sociocultural traz para o ensino e aprendizagem de LE uma perspectiva mais unificada na qual professor e aprendizes são vistos como participantes ativos e a aprendizagem como um desafio colaborativo. A aprendizagem e o desenvolvimento, 
conforme Vygotsky (1998), estão inter-relacionados desde o primeiro dia de vida do indivíduo. A fim de estabelecer a relação entre aprendizagem e desenvolvimento, Vygotsky cria o conceito de Zona de Desenvolvimento Proximal (ZDP). A ZDP é definida como a distância entre o nível atual de desenvolvimento, determinado pela independência em resolver um problema, e o nível de desenvolvimento potencial, caracterizado pela resolução de um problema sob a supervisão de um adulto ou em colaboração com parceiros mais capazes. A ZDP vem a ser a metáfora para a análise de como as formas de mediação são internalizadas pelos indivíduos (LANTOLF, 2000; PINHO; LIMA, 2009).

No contexto colaborativo da aprendizagem, Wood, Bruner e Ross (1976) criam o termo andaimento para o processo interativo de negociação, no qual o especialista acessa o nível de competência do aprendiz e escolhe o tipo de ajuda necessária para que ele complete uma tarefa. O especialista toma controle de partes da tarefa que estão além do nível atual de competência do aprendiz, passando-lhe gradualmente a responsabilidade de completá-la conforme a sua competência evolui. $\mathrm{O}$ andaimento pode, assim, promover o movimento da colaboração para a internalização (WOOD, BRUNER; ROSS, 1976; HALL, 2001).

Esta visão teórica, portanto, integra o ensino e aprendizagem de LE, com papéis ativos não só para o professor, como também para o aluno, na perspectiva de uma aprendizagem como uma atividade colaborativa. As realizações dos aprendizes não são produto apenas da aptidão, background e motivação individual, mas também dependem da estrutura social e linguística nas quais a sua aprendizagem acontece. Desse modo, a escolha de quais atividades aplicar em sala de aula e como prover suporte possui grande importância para o sucesso educacional de nossos alunos (GIBBONS, 2002; LIMA; PINHO, 2009). Segundo Lima e Costa (2010, p. 169) é papel do professor "selecionar tópicos e tarefas que motivarão seus alunos, oferecendo-lhes desafio (...) para que haja desenvolvimento. A língua torna-se, então, um veículo para atingir resultados nas tarefas, e a ênfase está no significado e na comunicação".

Ainda com base na teoria sócio-histórica vygostkiana, Broch (2008) analisou como adolescentes brasileiros estudantes de língua inglesa realizaram uma atividade de escrita coletiva de um texto teatral em língua inglesa em ambiente digital. $\mathrm{O}$ ambiente virtual de aprendizagem (AVA) utilizado foi o ALED (www.ufrgs.br/aled), fruto do projeto de pesquisa do Instituto de Letras/UFRGS que foca o Ensino e a Aprendizagem de Línguas Estrangeiras em Ambiente Digital. Para investigar o processo interativo de escrita coletiva, foram utilizadas como unidades de análise as inserções e alterações de parágrafo efetuadas por duplas de alunos no texto coletivo durante o processo. Foram identificadas duas formas de participação: a ativa, de construção colaborativa de conhecimento, e a marginal, em que não há um esforço em conjunto para alcançar um objetivo em comum, mantendo-se apenas uma participação aparente.

Segundo Broch (2008), as alterações são um processo de revisão do aluno na produção coletiva e ocorreram de modo espontâneo, voluntário e consciente, evidenciando reflexão-na-ação, que em algumas situações resultou no uso da metafala. A escrita coletiva em ambiente digital favorece o surgimento de ZDPs entre pares e é coletiva no momento em que mais de um aluno altera o mesmo parágrafo. Numa ZDP coletiva, as identidades dos participantes se confundem e o suporte é oferecido ora por um, ora por outro, consistindo em pedido de ajuda, oferecimento de ajuda, solicitação da atenção do outro quanto ao uso correto de estruturas linguísticas e resolução de problemas em conjunto. $\mathrm{O}$ editor colaborativo de texto oportuniza que o processo de escrita coletiva seja visualizado por todos simultaneamente, possibilitando que 
indivíduos com menor conhecimento iniciem a sua participação através da observação e gradualmente possam aumentar o seu campo de ação. Assim, alunos de diferentes níveis de proficiências podem aprender uns com os outros. A mediação social pode vir não só de um especialista como o professor, mas até dos pares menos proficientes. Além de todos esses fatores, deve-se avaliar também que ferramentas tecnológicas usar e quais tarefas elaborar a partir desses recursos para que a natureza do processo comunicativo seja desencadeada.

Os processos que ocorrem durante a aprendizagem no ambiente digital estão inseridos em um arcabouço temporal e espacial diferenciado que cria uma mobilidade constante, uma flexibilidade de acesso, produção e interação e uma alinearidade temporal geradora da metamorfose permanente que Waquil e Behar (2009) denominaram de presenteísmo: os dados podem ser modificados e questionados a qualquer instante, sendo a intervenção seguida por novos questionamentos, de uma forma contínua e rápida. A interação cognitivo-social ativa mais ou menos visível dos participantes produz a inteligência coletiva (LÉVY, 2007), pela sinergia formada a partir das trocas produzidas em várias direções entre os participantes da comunidade e pela reflexão favorecida pelo ir e voltar às suas próprias postagens e às alheias. Os participantes tornam-se leitores e autores, realizando seus próprios percursos hipertextuais dentro do ambiente. Esse ambiente digital também se constitui em um espaço social, no qual o principal é a qualidade da interação produzida e não somente a da interface, de forma a facilitar a aprendizagem e a interação.

A seguir, analisaremos uma etapa de um experimento realizado com alunos de um curso de graduação em Letras, em uma disciplina a distância, enquanto realizam, em meio virtual, reformulações síncronas em pares, a fim de se discutir o processo de reformulação cooperativa de textos escritos.

\section{A reformulação cooperativa ${ }^{1}$ em ambiente digital}

Pensando nas questões relacionadas a este trabalho tais como a proposição de tarefas que promovam autonomia e assim fomentem o papel ativo de um novo perfil de aluno disposto a lidar com as características do meio digital, foi realizada uma pesquisa focalizada em uma tarefa de reformulação colaborativa de texto em meio virtual. Para tanto, foi utilizada a ferramenta ETC ${ }^{[1]}$ como mecanismo vetor digital de reformulação colaborativa em uma turma de sete aprendizes de inglês como língua estrangeira, em contexto universitário. Tal ferramenta, concebida inicialmente para a produção de textos coletivos, possibilita edição, inserção de parágrafos e seções, além de manter histórico com todas as alterações realizadas no texto. Nessa pesquisa, a ETC foi aplicada na etapa de reformulação do texto, inicialmente escrito individualmente pelos alunos. Essa etapa consistia no momento de avaliação por parte dos leitores do texto, que tinham a oportunidade de prover feedback de forma colaborativa, editando o texto original e fornecendo comentários.

\footnotetext{
1 Apesar de alguns autores fazerem distinção entre os termos cooperação e colaboração, no presente estudo os apresentaremos como sinônimos tendo em vista que ambas as abordagens "têm o potencial de favorecer a interação e de proporcionar aos alunos um papel mais ativo no processo de aprendizagem" (FIGUEIREDO, 2006, p. 20).
} 
Visto que uma das investigações iniciais da pesquisa consistia em analisar de que modo os alunos tomavam decisões acerca dos textos do colega, o foco aqui é examinar em que medida a tarefa promoveu autonomia do aprendiz, acostumado, muitas vezes, a um ambiente tradicional de ensino no qual seu papel é de mero repositório de informações.

Os alunos tiveram de proporcionar sugestões e/ou críticas a fim de influenciarem no processo de correção/reformulação de textos. Nesse caso, a ferramenta digital se tornou um recurso facilitador para estimular a discussão dos informantes, sem que houvesse necessariamente presença física entre os alunos quando dos momentos de edição textual. As interações puderam ser inclusive conduzidas de modo síncrono através de um programa de comunicação síncrona, Skype ${ }^{[2]}$, facilitando o processo de discussão sobre as produções textuais, que se deu sempre entre dois ou três alunos.

A produção de textos concentrou-se na elaboração de resenhas críticas sobre cinema, resenhas críticas sobre artigo científico e fanfictions, sendo o último gênero o foco deste trabalho. A escolha de fanfictions se deu justamente por ser esse um gênero discursivo típico da internet. Tal gênero se caracteriza por englobar textos escritos por fãs de ícones culturais populares e midiáticos. Nessas composições há uma extensão da sinopse de um seriado, por exemplo, estabelecimentos de novas relações entre os personagens (BLACK, 2007) e ampliação de sequências ou criação de uma história prévia para o objeto original.

$O$ gênero fanfiction segue a tipologia narrativa em termos de presença de personagens, sinopse e contexto (espaço). Além disso, o desenvolvimento do texto é geralmente vinculado ao feedback do leitor, que sugere e incentiva o autor. Por isso, são muitas vezes descritas como histórias seriais que se desenvolvem aguçando a expectativa do leitor. Desse modo, esse gênero textual é propício a ser parte da temática de uma tarefa que justamente visa à reformulação colaborativa, pois sua continuação está relacionada ao feedback fornecido pelos leitores.

As interações estabelecidas pelos aprendizes através do Skype foram redirecionadas à professora da disciplina, uma das pesquisadoras do presente trabalho, a fim de que pudessem ser analisadas posteriormente, a partir de um viés qualitativo. Ficou a cargo dos estudantes o envio ou não de tal material (editado ou original) para fins de pesquisa.

Para exemplificação de alguns momentos em que houve vinculação entre as atitudes dos alunos e indícios de autonomia fomentados pela tarefa, incluímos em seguida trechos de uma conversa síncrona entre duas estudantes da turma, que discutiam o processo de reformulação das fanfictions escritas por seus colegas. A grafia original das postagens produzidas pelos alunos foi preservada e reproduzida aqui sem correções.

No excerto abaixo, logo no início da interação síncrona via Skype, quando as alunas começam a discutir seu processo de reformulação de uma fanfiction, em pares elas negociam qual deve ser seu primeiro texto de análise. Tal fato se relaciona ao índice proposto que envolve a tomada de decisão, iniciador de um encadeamento interacional. Em dado momento, observamos que os aprendizes já iniciam um procedimento de autonomia cognitiva, no qual realizam decisões conjuntas, baseadas em suas próprias escolhas enquanto alunas de língua estrangeira em ambiente digital (Quadro 1). 


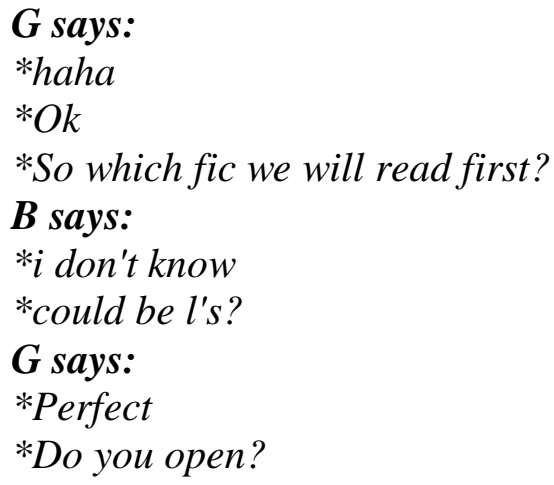

Quadro 1 - Exemplo de interação entre duas alunas em que há tomada de decisões em conjunto

Em seguida, a aluna B posta uma parte de uma fanfiction escrita por uma colega, dentre outros trechos nos quais ambas discutem a estrutura textual, aponta para uma questão gramatical relativa ao uso do pronome e pede a certificação de sua interlocutora a fim de promover uma reformulação baseada em escolhas cooperativas. Nesse momento (Quadro 2), o discurso sobre a negociação da aprendizagem vem à tona, pois a presença do outro se faz relevante no processo de reflexão e reelaboração de conceitos.

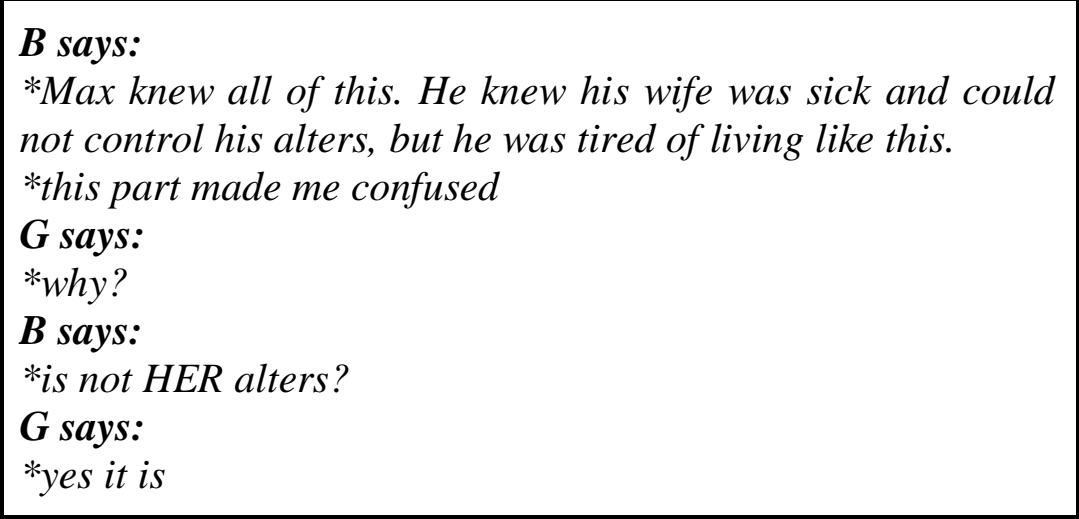

Quadro 2 - Reflexão e auxílio sobre estrutura textual

Durante todo o processo de discussão e reelaboração do texto, as alunas dão andaimento à atuação da outra ao propor edições, conferir a concordância com a colega e realizar as modificações de modo colaborativo, tomando assim decisões de modo autônomo, sem intervenção direta do professor.

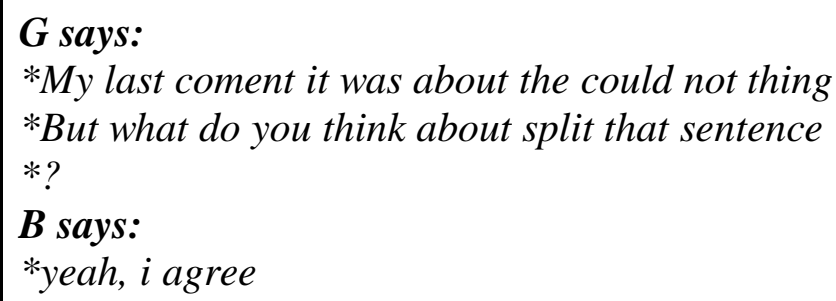

Quadro 3: Andaimento e decisões autônomas 
No excerto seguinte (Quadro 4), uma das alunas inclusive menciona o mecanismo de noticing (SWAIN; LAPKIN, 2001), segundo o qual o aprendiz percebe lacunas na sua produção. Nesse caso, baseado na análise da produção alheia, a aluna tem oportunidade de observar seus próprios erros ao entrar em contato com o processo de leitura, exame e reformulação. Há uma tomada de consciência em relação às lacunas na produção do próprio aprendiz a partir do exame de outro texto.

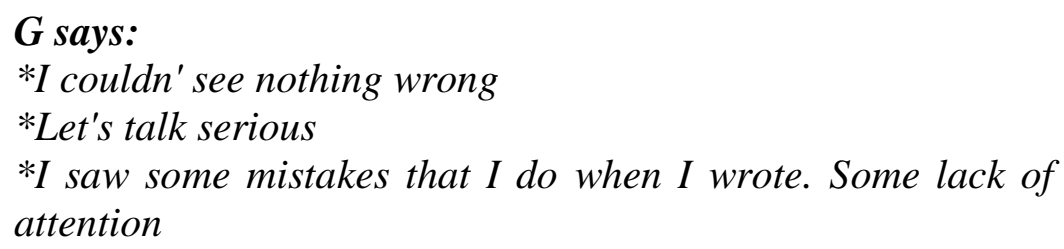

Quadro 4: Noticing - o aprendiz percebe lacunas em seu aprendizado

Tais dados refletem a relação encontrada entre os indícios de autonomia e a atuação dos alunos durante suas interações síncronas no ambiente digital.

\section{Considerações Finais}

$\mathrm{Na}$ análise completa dos dados provenientes das interações síncronas e das postagens assíncronas, foram encontradas evidências de que o ambiente online de aprendizagem fomenta a participação do aluno de modo ativo e autônomo na reelaboração de textos dos seus colegas, visto que suas escolhas linguísticas são negociadas cooperativamente. Desse modo, baseando-se na busca por índices de autonomia, no decorrer das interações entre os alunos, pudemos observar indícios de potencialização do papel autônomo do aluno a partir de uma tarefa que requeria colaboração entre os aprendizes no meio digital.

O presente estudo nos mostra que os aprendizes em suas interações olharam novamente para as suas produções escritas através de uma nova perspectiva - a perspectiva de um revisor - propondo, assim, mudanças ao negociar sentidos com um colega. Logo, a escrita colaborativa mobilizou a participação ativa dos aprendizes ao se engajarem na discussão sobre o texto e, posteriormente, na reelaboração do mesmo, o que possibilitaria a sua publicação. Ao aliar modalidades síncronas e assíncronas, além de tecnologias diversas, a tarefa colaborativa se tornou mais completa no ambiente digital, permitindo ao aluno não somente realizar as alterações as quais julgava necessárias no texto, mas também conversar sobre elas com seus pares.

Contudo, vemos muitas práticas tradicionais de ensino que tendem a valorizar o produto originado pelos alunos, muitas vezes, de modo passivo e individual. Tais práticas não levam em conta os processos de criação e reelaboração, os quais podem ser ativos e estabelecidos em aula a partir de parcerias provocadoras, que desse modo iniciam o seu agir autônomo. Por isso, a inclusão de tarefas como a exemplificada acima, nas quais os alunos atuam de modo colaborativo e autônomo em ambiente digital, pode favorecer processos de aprendizagem centrados no próprio aprendiz. Nesse caso, há uma mudança de paradigma voltada à percepção de alunos e professores como agentes cooperativos no processo de ensino de aprendizagem, de modo a ressaltar a posição do aprendiz como um sujeito responsável por seu próprio aprendizado. 


\section{Notas}

[I] Editor de texto coletivo desenvolvido pelo NUTED - Núcleo de Tecnologia Digital aplicada à Educação - da Universidade Federal do Rio Grande do Sul: http://www.nuted.ufrgs.br/etc/

${ }^{22}$ Skype - https://www.skype.com/

\section{Referências}

BARCELLOS, P. S. C. C. O processo de criação colaborativa de tarefas em língua estrangeira em ambiente digital por professores em formação. Tese de Doutorado. São Leopoldo: Programa de Pós-Graduação em Linguística Aplicada - UNISINOS, 2017.

BENSON, P. The philosophy and politics of learner autonomy. In: BENSON, P.; VOLLER, P. Autonomy and independence in language learning. London: Longman, 1997. p. 18-34.

BENSON, P. Teaching and Researching: Autonomy in Language Learning. Malaysia: Pearson Education Limited, 2001.

BLACK, R. Digital design: English language learners and reader reviews in online fanfiction. In: KNOBEL, M.; LANKSHEAR, C. (Ed.). A New Literacies Sampler. New York: Peterlang, 2007. p. 115- 136.

BREEN, M.; CANDLIN, C. The essentials of a communicative curriculum in language teaching. Applied Linguistics, v.1, n.2, p. 89-112, 1980.

BREEN, M.; MANN, S.J. Shooting arrows at the sun: perspectives on a pedagogy for autonomy. In: BENSON, P.; VOLLER, P. Autonomy and independence in language learning. London: Longman, 1997. p.133-149.

BROCH, I. Escrita coletiva de texto teatral em língua inglesa em ambiente de aprendizagem: o foco do aluno no processo. Dissertação de Mestrado. Instituto de Letras/UFRGS. Porto Alegre, 2008

BYGATE, M.; SKEHAN, P; SWAIN, M. Researching pedagogic tasks: second language learning, teaching and testing. Harlow: Longman, 2001.

DONATO, R. Aspects of collaboration in pedagogical discourse. In: Annual Review of Applied Linguistics, v. 24, p. 284-302, 2004

FIGUEIREDO, F. J. Q. A aprendizagem colaborativa: algumas considerações conceituais e terminológicas. In: FIGUEIREDO, F. J. Q. (Org.). A aprendizagem colaborativa de línguas. Goiânia: Editora UFG, 2006. p.11-45.

FREIRE, P. A Pedagogia da Autonomia - Saberes necessários à prática educativa. São Paulo: Paz e Terra, 1996.

GIBBONS, P. Scaffolding Language: Scaffolding Learning: Teaching Second Language Learners in the Mainstream Classroom. Heinemann: Portsmouth, NH, 2002.

HALL, J. Methods for teaching foreign languages: creating a community of learners in the classroom. New Jersey: Merril, 2001.

LANTOLF, J. P. (Ed.). Sociocultural Theory and Second Language Learning. Oxford: Oxford University Press, 2000.

LÉVY, P. A inteligência coletiva: por uma antropologia do ciberespaço. 5. ed. São Paulo: Edições Loyola, 2007.

LIMA, M.; COSTA, P. O diálogo colaborativo como ação potencial para a aprendizagem de línguas. Trabalhos em Linguística Aplicada, v.49, n.1, p.167-184, jan./jun. 2010. 
LITTLEWOOD, W. Defining and developing autonomy in East Asian contexts. Applied Linguistics, v.20, n. 1, p. 71-94, 1999.

NEVADO, R. Espaços interativos de construção de possíveis: uma nova modalidade de formação de professores. Tese de Doutorado. Porto Alegre: PGIE-UFRGS, 2001.

NICOLAIDES, Christine Siqueira. A busca da aprendizagem autônoma de língua estrangeira no contexto acadêmico - tese de doutorado. Porto Alegre: UFRGS, 2003.

NUNAN, D. Designing tasks for the communicative classroom. Cambridge: Cambridge University, 1993.

OXFORD, R. Toward a More Systematic Model of L2 Learner Autonomy. In: PALFREYMAN, D.; SMITH, R. Learner Autonomy Across Cultures. Great Britain: Palgrave Macmillan, 2003. p. 75 - 91.

PAPERT, S. A Máquina das Crianças. Porto Alegre: Artmed, 1994.

PINHO, I. E LIMA, M. A Fala Privada e a Aprendizagem de Línguas. Organon, n. 46, v.23, p.161-173, 2009.

POLONIA, E. Parâmetros para Procedimentos Pedagógicos na Aprendizagem de Inglês como Língua Estrangeira em uma Rede Telemática.Tese de Doutorado. Porto Alegre: PGIE-UFRGS, 2003.

POLONIA, E. Procedimentos pedagógicos para a aprendizagem de línguas estrangeiras em ambiente digital. In: LIMA, M.; GRAÇA, M. (Org.). Ensino e aprendizagem de língua estrangeira: relações de pesquisa Brasil/Canadá Porto Alegre: Armazém Digital, 2007. p. 127-148.

RICHARDS, J.; RODGERS, T. Approaches and methods in language teaching: A description and analysis. Cambridge: Cambridge University Press, 1986.

SWAIN, M. Focus on form through conscious reflection. In: DOUGHTY C.; WILLIAMS, J. Focus on form in classroom second language acquisition. Cambridge, Cambridge University,1998. p. 64-81.

SWAIN, M.; LAPKIN, S. Focus on form through collaborative dialogue: exploring task effects. In: BYGATE, M.; SKEHAN, P.; SWAIN, M. Researching pedagogic tasks: second language learning, teaching and testing. Essex: Pearson Education, 2001. p. 99118.

VETROMILlE-CASTRO, R. A Interação Social E O Benefício Recíproco Como Elementos Constituintes De Um Sistema Complexo Em Ambientes Virtuais De Aprendizagem. Tese de Doutorado. Porto Alegre: PGIE-UFRGS, 2007.

VYGOTSKY, L. A formação social da mente: o desenvolvimento dos processos psicológicos superiores. 6 ed. São Paulo: Martins Fontes, 1998.

WAQUIL, M.; BEHAR, P. Princípios da pesquisa científica para investigar ambientes virtuais de aprendizagem sob o ponto de vista do pensamento complexo. In: BEHAR, P.(Org.). Modelos pedagógicos em educação a distância. Porto Alegre: Artmed, 2008.

WOOD, D.; BRUNER, J.; ROSS, G. The role of tutoring in problem solving. Journal of Child Psychology and Psychiatry, v. 17, p. 89-100, 1976. 